\title{
Clinical efficacy and tolerability of Gabapentinoids with current prescription patterns in patients with Neuropathic pain
}

\author{
Abida Shaheen ${ }^{1}$, Syed Mahboob Alam², \\ Arsalan Ahmad ${ }^{3}$, Moosa Khan ${ }^{4}$
}

\begin{abstract}
Objective: To investigate the current dosing regimens of gabapentinoids in Pakistani patients with neuropathic pain and to compare their clinical efficacy and tolerability in terms of pain relief and adverse effects using difference in pain score as a treatment outcome.

Methods: This observational, prospective study was conducted in 320 patients with neuropathic pain from August 2016 to March 2018 at Basic Medical Sciences Institute (BMSI), Karachi in collaboration with Shifa International Hospital and Benazir Bhutto Hospital, Islamabad. Demographic data, treatment-related adverse effects and pain intensity was documented at recruitment and follow up visits at two, four and eight weeks. Discontinuation due to adverse effects and lack of efficacy were also recorded. Data was entered and analyzed using SPSS version 22.

Results: Mean age of patients was $52.57 \pm 12.47$ and the most common ethnicity were Punjabi speaking population (66\%). Diabetic neuropathy (51\%) was the most common etiology followed by radicular pain (25\%). Mean dosages of pregabalin and gabapentin were $114 \mathrm{mg}$ and $470 \mathrm{mg}$ respectively. Mean pain score was significantly reduced by gabapentinoids $(<0.001)$. Dizziness, drowsiness and somnolence were frequent adverse effects. Common dosages for pregabalin and gabapentin were $75 \mathrm{mg} / \mathrm{day}$ and $300 \mathrm{mg} /$ day respectively.

Conclusion: Current dosing regimens of gabapentinoids in Pakistani patients with neuropathic pain were found to be efficacious at low dosages in comparison to international recommended dosages. Gabapentin and pregabalin were both similar in terms of reducing pain score but onset of pain relief was relatively faster with pregabalin. Dizziness, drowsiness and somnolence were frequently reported with both gabapentinoids; however, visual blurring, ataxia and weight gain were observed only with the use of pregabalin. Adverse effects are frequently observed with gabapentinoids which necessitates reverting back to low dosages or switching to other drugs for pain relief.
\end{abstract}

KEYWORDS: Gabapentinoids, Neuropathic pain, Current dosages, Pain relief, Adverse effects.

doi: https://doi.org/10.12669/pjms.35.6.652

How to cite this:

Shaheen A, Alam SM, Ahmad A, Khan M. Clinical efficacy and tolerability of Gabapentinoids with current prescription patterns in patients with Neuropathic pain. Pak J Med Sci. 2019;35(6):1505-1510. doi: https://doi.org/10.12669/pjms.35.6.652

This is an Open Access article distributed under the terms of the Creative Commons Attribution License (http://creativecommons.org/licenses/by/3.0), which permits unrestricted use, distribution, and reproduction in any medium, provided the original work is properly cited.

Correspondence:

Dr. Abida Shaheen, MPhil, Associate Professor,

Pharmacology \& Therapeutics,

Shifa College of Medicine,

Shifa Tameer-e-Millat University,

Islamabad, Pakistan.

Email: abida.scm@stmu.edu.pk

* Received for Publication:

* Revision Received:

* Revision Accepted:
March 2, 2019

July 12, 2019

August 5, 2019

\section{INTRODUCTION}

Neuropathic pain $(\mathrm{NeP})$ is defined as pain caused by a lesion or disease of the somatosensory system. ${ }^{1,2}$ Multiple heterogeneous etiologies of central or peripheral origin precipitate neuropathic pain and severely affect the quality of life. ${ }^{3}$ Global prevalence of neuropathic pain ranges from 6.9$10 \%$ with spinal cord injury accounting for $40 \%$ cases. ${ }^{4,5}$ The second most common etiology for $\mathrm{NeP}$ 
is diabetic peripheral neuropathy (DPN) which is present in $22-28 \%$ of diabetic population. ${ }^{6-9}$

The first line treatment options for the management of $\mathrm{NeP}$ include gabapentinoids, tricyclic antidepressants, serotonin-noradrenaline reuptake inhibitors and opioids. Pregabalin and gabapentin are the two gabapentinoids which have been approved and widely prescribed for $\mathrm{NeP}$. These are derivatives of the inhibitory neurotransmitter gamma-aminobutyric and bind to presynaptic $a_{2-}$ Ssubunit of voltage-dependent calcium channels which leads to reduced neurotransmitter release resulting in attenuation of post-synaptic excitability. ${ }^{10}$

Pregabalin has been approved for the treatment of neuropathic pain syndromes with considerable efficacy in dosages range from 150mg up to $600 \mathrm{mg} /$ day depending on patients' therapeutic response and tolerability. On the other hand, gabapentin is prescribed with starting dose of $300 \mathrm{mg}$ and it is then titrated up to $1800-3600 \mathrm{mg} /$ day divided in three doses in patients with normal renal function. ${ }^{11,12}$ Pregabalin requires less frequent daily dosing and comparable efficacy to gabapentin owing to its higher potency, linear pharmacokinetics and greater bioavailability. ${ }^{11,13}$

Most of the clinical studies involving administration of gabapentinoids have reported dizziness, drowsiness and somnolence as the most frequent dose-dependent adverse effects which occur in about every fourth patient. Other common adverse effects include nervousness, headache, blurred vision, dry mouth, peripheral edema, weight gain, constipation, blurred vision, decreased motor coordination and ataxia in $1-10 \%$ of patients. ${ }^{11,14,15}$

Multiple factors make $\mathrm{NeP}$ difficult to manage including heterogeneous diagnostic criteria, inadequate response to existing treatment options and variable efficacy of the available drugs. Current clinical practices are based on randomized clinical trials and clear recommendations on dosages are not available. ${ }^{11}$ There are considerable interindividual variations in therapeutic response to gabapentinoids hence prescribing strengths of these drugs also vary and physicians mostly rely on their clinical experience for optimal dosages. ${ }^{10,12,14}$ Current treatment dosages of gabapentinoids in Pakistani population are different from international guidelines. ${ }^{12}$ Scarce data is available from Pakistan about the clinical efficacy and tolerability of gabapentinoids despite routine clinical use thus observational, noninterventional studies are required to observe the dosage patterns and therapeutic effec- tiveness of gabapentinoids in clinical practice.

With this background, aim of this study was to explore the current dosing regimens of pregabalin and gabapentin in patients with neuropathic pain. Furthermore, our study also compared the efficacy and tolerability of gabapentinoids in terms of pain relief and adverse effects using difference in pain score as a treatment outcome.

\section{METHODS}

This observational, prospective study was carried out in outpatient pain clinics over a period of 20 months from August 2016 to March 2018 at Shifa International Hospital, Islamabad, Benazir Bhutto Hospital, Rawalpindi in collaboration with Basic Medical Sciences Institute, Karachi. Study protocol was approved by Institutional Review Board \& Ethics Committee. Three hundred and twenty patients of either gender, aged $\geq 18$ years were included after obtaining written and verbal informed consent with established diagnosis of neuropathic pain due to heterogeneous etiologies. Patients' pain scores at the time of recruitment were $\geq 40 \mathrm{~mm}$ on the $100 \mathrm{~mm}$ Visual Analog Scale (VAS) of the Short Form-McGill Pain Questionnaire and an average pain score $\geq 4$ on an 11-point Numeric Rating Scale. Patients with creatinine clearance less than $60 \mathrm{ml} / \mathrm{min}$ or any other renal insufficiency and gastrointestinal diseases that could interfere with the absorption of drugs were excluded from the study. Patients' demographic data, clinical history and all relevant information related to neuropathic pain were recorded in a detailed structured questionnaire.

The patients who were receiving different dosages of pregabalin or gabapentin in QD, BID and TID regimen by prescribing clinicians were placed into dosing groups of pregabalin (50-75, >75$150,>150-200$ and $>200-300 \mathrm{mg})$ and gabapentin (0$200,>200-300,>300-600,>600-900 \mathrm{mg})$. The patients were followed for primary efficacy outcomes by measuring pain scores by VAS and NRS at baseline and later at 2-, 4- and 8 weeks' follow-up visits. All the clinical progress and adverse effects since the commencement of these medications were recorded for the full duration of study. Discontinuation of gabapentinoids due to lack of efficacy, inadequate response and adverse effects were also recorded. For this study we estimated the sample size using a previously published paper $^{9}$ which compared the pain scores of gabapentinoids using Visual Analogue Scores. To detect of a difference of 2.28 points in pain scores between pregabalin treated group (previous reported estimate 38.90 5.70 ) 
and gabapentin treated group (previous reported estimate: $41.62 \pm 4.79$ ); with $95 \%$ confidence level and $80 \%$ power of the test, we used OpenEpi software and the minimum sample required for this study was 142 with 71 individuals in each group.

Statistical analysis: Exposure to gabapentinoids and outcomes (clinical efficacy, adverse effects) were recorded for all those patients who continued the treatment till 8-weeks of the study. Clinical efficacy was defined as a change in mean pain score from baseline to a clinically meaningful reduction of $\geq 30 \%$ or $\geq 50 \%$. $^{16}$ Data was converted to electronic files using the Microsoft Excel Software and Excel files were imported to Statistical Package for Social Sciences (SPSS) version 22 for analysis. The quantitative variables like age, dosage of drugs, time to onset of pain relief and difference in pain scores were presented with Mean and Standard Deviations (SD). The qualitative variables such as ethnicity, gender and adverse effects were reported in frequency and percentage. For making compari-
Table-I: Demographic data.

\begin{tabular}{ll}
\hline Age (years) mean (SD) & $52.57 \pm 12.47$ \\
Ethnicity, $\boldsymbol{n}(\%)$ & \\
Punjabi & $167(66)$ \\
Pathan & $70(28)$ \\
Urdu Speaking & $15(6)$ \\
Gender, $\boldsymbol{n}(\%)$ & \\
Male & $92(36)$ \\
Female & $160(64)$ \\
\hline
\end{tabular}

son of pain scores, time to relief in pain between groups i.e. pregabalin and gabapentin, we used two independent samples Student ' $t$ ' test. Statistical significance was set at $p$-value less than 0.05 .

\section{RESULTS}

Three hundred and twenty patients were enrolled in the study out of which sixty-eight patients could not complete the study due to various reasons. Six-

Table-II: Dosage groups and mean dosages of Gabapentinoids for different etiologies of NeP.

\begin{tabular}{|c|c|c|c|c|c|c|c|c|c|c|c|}
\hline \multirow{2}{*}{ Etiology } & \multirow{2}{*}{$\begin{array}{c}\text { Frequency } \\
n(\%)\end{array}$} & \multicolumn{4}{|c|}{$\begin{array}{l}\text { Pregabalin Dose } m g / d \\
\text { (n) }\end{array}$} & \multirow{2}{*}{$\begin{array}{c}\text { Mean } \\
\text { Pregabalin } \\
\text { dose }(\mathrm{mg} / \mathrm{d}) \\
\text { Mean }( \pm S D) \\
\end{array}$} & \multicolumn{4}{|c|}{$\begin{array}{l}\text { Gabapentin Dose } m g / d \\
(n)\end{array}$} & \multirow{2}{*}{$\begin{array}{c}\text { Mean } \\
\text { Gabapentin } \\
\text { dose }(m g / d) \\
\text { Mean }( \pm S D)\end{array}$} \\
\hline & & $50-75$ & $\begin{array}{l}>75- \\
150\end{array}$ & $\begin{array}{l}>150- \\
200\end{array}$ & $\begin{array}{l}>200- \\
300\end{array}$ & & $\begin{array}{c}0- \\
200\end{array}$ & $\begin{array}{c}>200- \\
300\end{array}$ & $\begin{array}{c}>300- \\
600\end{array}$ & $\begin{array}{c}>600- \\
900\end{array}$ & \\
\hline $\begin{array}{l}\text { Diabetic } \\
\text { Neuropathy }\end{array}$ & $128(50.7)$ & 81 & 28 & 5 & 1 & $102.04 \pm 46.14$ & 1 & 7 & 5 & 0 & $\begin{array}{c}363.64 \pm \\
167.87\end{array}$ \\
\hline Radicular Pain & $62(24.60)$ & 17 & 10 & 8 & 2 & $139.19 \pm 70.60$ & 6 & 4 & 7 & 8 & $\begin{array}{c}578.26 \pm \\
295.15\end{array}$ \\
\hline $\begin{array}{l}\text { Intercostal } \\
\text { Neuralgia }\end{array}$ & $7(2.77)$ & 2 & 2 & 2 & 0 & $154.17 \pm 51.03$ & 1 & 0 & 0 & 0 & 200 \\
\hline CRPS & $7(2.77)$ & 4 & 1 & 1 & 1 & $128.57 \pm 95.12$ & 0 & 0 & 0 & 0 & - \\
\hline Fibromyalgia & $6(2.38)$ & 3 & 2 & 0 & 0 & $105.00 \pm 44.72$ & 1 & 0 & 0 & 0 & 200 \\
\hline $\begin{array}{l}\text { Post stroke } \\
\text { neuralgia }\end{array}$ & $2(0.79)$ & 0 & 2 & 0 & 0 & 150 & 0 & 0 & 0 & 0 & - \\
\hline $\begin{array}{l}\text { Trigeminal } \\
\text { Neuralgia }\end{array}$ & $5(1.98)$ & 5 & 0 & 0 & 0 & $85.00 \pm 13.69$ & 0 & 0 & 0 & 0 & - \\
\hline $\begin{array}{l}\text { Carpal Tunnel } \\
\text { Syndrome }\end{array}$ & $5(1.98)$ & 2 & 1 & 1 & 1 & $170.00 \pm 102.16$ & 0 & 0 & 0 & 0 & $250 \pm 70.71$ \\
\hline $\begin{array}{l}\text { Guillain Barre } \\
\text { Syndrome }\end{array}$ & $3(1.19)$ & 0 & 1 & 0 & 0 & 150 & 1 & 0 & 0 & 1 & $500 \pm 565.69$ \\
\hline CKD & $9(3.57)$ & 5 & 0 & 1 & 1 & $117.86 \pm 99.70$ & 1 & 1 & 0 & 0 & $250 \pm 70.71$ \\
\hline $\begin{array}{l}\text { Post-surgical } \\
\text { pain }\end{array}$ & $9(3.57)$ & 5 & 1 & 2 & 0 & $115.63 \pm 74.33$ & 0 & 0 & 0 & 1 & 900 \\
\hline $\begin{array}{l}\text { Post } \\
\text { Chemotherapy }\end{array}$ & $5(3.57)$ & 1 & 3 & 0 & 0 & $125.00 \pm 50.00$ & 0 & 1 & 0 & 0 & 300 \\
\hline Others & $4(1.58)$ & 4 & 0 & 0 & 0 & $81.25 \pm 23.94$ & 0 & 0 & 0 & 0 & - \\
\hline
\end{tabular}


teen of these patients were lost to follow up during the study whereas twenty-four patients showed inadequate response to gabapentinoids and were switched to other drugs. Twenty-eight patients developed severe dizziness or drowsiness and could not tolerate these adverse effects. Two hundred and fifty-two patients completed the study and were evaluated for efficacy and tolerability measures.

Mean age of these study participants was 52.57 \pm 12.47 . Most common ethnic group among our study participants were Punjabi speaking population $(66 \%)$ followed by Pathan $(28 \%)$ and Urdu speaking participants (6\%). Number of females was almost twice as the number of male participants. Results of the demographic data are summarized in Table-I.

Two hundred and six study participants $(81.74 \%)$ received pregabalin whereas forty six (18\%) patients received gabapentin for different types of neuropathic pain. The most common etiologies for neuropathic pain were diabetic neuropathy and radicular pain with prevalence of $51 \%$ and
$24 \%$ respectively. Frequencies of etiologies, mean dosages and dosage arms of both gabapentinoids are summarized in Table-II.

Mean dosages of pregabalin in all patients was114.25 $\pm 59.58 \mathrm{mg}$ whereas mean dosages required by Urdu speaking, Punjabi and Pathan for all etiologies were $101.79 \pm 71.03,114.24 \pm 59.58$ and $116.56 \pm 54.72 \mathrm{mg}$ respectively with a $p$ value of 0.293 . Furthermore, mean dosage requirements of gabapentin were $470.48 \pm 277.45 \mathrm{mg}$ in all patients. Mean dosages of gabapentin were $486.96 \pm 268.83 \mathrm{mg}$ in Punjabi speaking and 555.56 $\pm 292.02 \mathrm{mg}$ in Pushto speaking population with a $\mathrm{p}$ value of $<0.001$.

Dizziness, drowsiness and somnolence were the most frequent adverse effects reported with both pregabalin and gabapentin. Frequencies of adverse effects reported are summarized in Table-III.

The mean pain score for all etiologies using the NRS scale after approximately two weeks' duration was reduced to 1.92 in patients taking pregabalin and 1.93 in patients receiving gabapentin. These results are summarized in Table-IV.

Table-III: Adverse effects and inadequate response reported with Gabapentinoids.

\begin{tabular}{llcc}
\hline & \multicolumn{2}{c}{ Adverse effects observed in patients who completed the study $(n=252)$} \\
\hline Drugs & Adverse effects & $n(\%)$ & Mean dose $\pm S D(m g / d)$ \\
\hline Pregabalin & Dizziness, Drowsiness, Somnolence & $58(23)$ & $95.43 \pm 53.06$ \\
& Visual Blurring & $3(1.19)$ & $125.00 \pm 90.14$ \\
& Ataxia & $4(1.58)$ & $56.25 \pm 10.83$ \\
Weight Gain & $1(0.39)$ & 300 \\
\hline
\end{tabular}

Patients' non-compliance due to severe adverse effects $(n=28)$

\begin{tabular}{|c|c|c|c|c|c|c|c|}
\hline & & & \multicolumn{2}{|l|}{$n(\%)$} & \multicolumn{3}{|c|}{ Mean dose $\pm S D(m g / d)$} \\
\hline Pregabalin & $15(54)$ & & & & \multicolumn{3}{|c|}{$112.00 \pm 48.17$} \\
\hline Gabapentin & $13(46)$ & & & & \multicolumn{3}{|c|}{$375.68 \pm 189.70$} \\
\hline \multicolumn{8}{|c|}{ Patients with inadequate response $(n=24)$} \\
\hline Pregabalin & $7(29)$ & & & & \multicolumn{3}{|c|}{$126.21 \pm 49.20$} \\
\hline Gabapentin & $17(71)$ & & & & \multicolumn{3}{|c|}{$325.58 \pm 162.73$} \\
\hline \multicolumn{8}{|c|}{ Lost to follow up $(n=16)$} \\
\hline Pregabalin & $4(25)$ & & & & \multicolumn{3}{|c|}{$106.28 \pm 80.24$} \\
\hline Gabapentin & $12(75)$ & & & & \multicolumn{3}{|c|}{$384.38 \pm 177.64$} \\
\hline \multicolumn{8}{|c|}{ Table-IV: Difference in pain score after use of Gabapentinoids. } \\
\hline Drugs & $\begin{array}{l}\text { Time to onset of pain } \\
\text { relief (days) }\end{array}$ & p-value & $\begin{array}{c}\text { Pain Score } \\
\text { Before }\end{array}$ & $\begin{array}{l}\text { Pain score } \\
\text { After }\end{array}$ & Difference & p-value & $\begin{array}{l}\text { Overall } \\
\text { p-value }\end{array}$ \\
\hline Pregabalin & $13.73 \pm 1.45$ & \multirow{2}{*}{$<0.001$} & $5.94 \pm 0.90$ & $1.92 \pm 0.83$ & $4.02 \pm 1.02$ & $<0.001$ & \multirow{2}{*}{$<0.001$} \\
\hline Gabapentin & $18.28 \pm 2.68$ & & $6.17 \pm 0.93$ & $1.93 \pm 0.68$ & $4.23 \pm 1.06$ & $<0.001$ & \\
\hline
\end{tabular}

Pak J Med Sci November - December 2019 Vol. 35 No. $6 \quad$ www.pjms.org.pk 1508 


\section{DISCUSSION}

In our study, majority of the participants belonged to Punjabi and Pushto speaking ethnic groups as these groups represent majority of population of Rawalpindi and Islamabad where this study was conducted. Number of female patients was almost twice than males and consistent with other studies conducted to compare prevalence of chronic pain in both genders concluding females have greater pain sensitivity, report pain more frequently and have a lower threshold for most types of pain including neuropathic pain. ${ }^{17}$

The mean dosages of pregabalin and gabapentin for all etiologies were $114.2 \pm 59.6$ and $470.5 \pm 277.45$ respectively. Furthermore, pregabalin frequency of administration was more which could be due to discrete pharmacokinetic advantages of pregabalin over gabapentin. ${ }^{10,13}$ According to international guidelines, gabapentinoids are minimally effective or ineffective at low dosages. ${ }^{18,19}$ In our study, most common dosage of pregabalin was $75 \mathrm{mg} /$ day and these findings are in contrast to the international guidelines which suggest minimum starting dose of $150 \mathrm{mg}$ and clinically effective dose at $300-600 \mathrm{mg} /$ day. ${ }^{13,18}$ Similarly, most patients taking gabapentin were given dosages of less than $900 \mathrm{mg} /$ day which are in disagreement to the international guidelines recommending $1800-3600 \mathrm{mg}$ for effective pain relief. ${ }^{10,11,19}$ Consistent with our findings, a recent study from Japan using hospital prescription database reported pregabalin daily maintenance dose of $127.8 \mathrm{mg}$ which was significantly lower than those reported in the USA and Europe, highlighting different dosage requirements in different populations. ${ }^{20}$

Our results showed that patients taking gabapentin and pregabalin for neuropathic pain showed a significant decrease in pain from a mean pain score of 6.2 to 1.9 and 5.9 to 1.9 after a mean duration of 18.28 and 13.73 days, respectively. These results of our study are in accordance with different studies where both drugs resulted in a mean decrease of pain intensity of approximately $30-50 \%$ in majority of the patients. ${ }^{13,21}$

Pregabalin was most commonly prescribed for diabetic neuropathy and the results of our study are consistent with other researches proving pregabalin as better choice as monotherapy in 75 to $300 \mathrm{mg} /$ day in early reduction of pain. ${ }^{13,18}$ Gabapentin was preferred for radicular pain management. There is limited literature on direct comparison between the two drugs for radicular pain but the results of our study are in accordance with other studies suggesting that gabapentin is more efficacious than prega- balin for radiculopathies and treatment should be commenced with gabapentin though its average daily dose was significantly lower in our study..$^{22,23}$

Neuropsychiatric adverse effects such as severe dizziness, drowsiness and somnolence were reported in $23 \%$ and $4 \%$ of patients receiving pregabalin and gabapentin, respectively. In our study, mean doses of patients with adverse effects were significantly less compared to the average doses in patients who did not report such adverse effects. Moreover, sixty-eight patients were not included for final analysis and main reasons for drop out were non-compliance due to severe adverse effects. Mean dosages of pregabalin and gabapentin were not similar in different ethnic population though not statistically significant. Some studies have suggested role of distinct genetic polymorphism for regulation of proteins for absorption, metabolism, and excretion and as transporter molecule at the site of action in different population which might result in variation of clinical response to these drugs. ${ }^{24,25}$

To our knowledge, there have been no studies from Pakistan to evaluate efficacy and tolerability of gabapentinoids in chronic NeP. We acknowledge potential limitations of the study as it was observational, time-bound and conducted in running OPDs hence it was not possible to categorize patients in equal groups for head to head comparison as the drugs and doses were selected by clinicians according to type and severity of NeP. However, potential strengths of our study were adjustment of other variables such as detailed documentation, regular follow-up and close monitoring of adverse effects.

\section{CONCLUSION}

In summary, effective dosing range of pregabalin and gabapentin was $114.2 \pm 59.6 \mathrm{ad}$ $470.5 \pm 277.45 \mathrm{mg} / \mathrm{d}$, respectively. Mean time in onset of relief of pain was less for pregabalin as compared to gabapentin $(<0.001)$. Pregabalin prescription rate was higher as compared to gabapentin. Majority of patients experienced dizziness, drowsiness and somnolence at low doses. Our study findings conclude that Pakistani patients respond to neuropathic pain at low dosages in comparison to international recommendations. Given routine clinical use of gabapentinoids, future clinical trials are required to define appropriate dosing regimens and molecular studies are needed to explore the role of polymorphism in Pakistani population and occurrence of adverse effects at low dosages.

Disclaimer: This study is part of a PhD project that had two co-authors as supervisors. 
Conflict of Interest: None.

Grant Support E Financial Disclosures: None.

\section{REFERENCES}

1. Treede RD, Jensen TS, Campbell JN, Cruccu G, Dostrovsky JO, Griffin JW, et al. Neuropathic pain: redefinition and a grading system for clinical and research purposes. Neurology. 2008;70(18):1630-1635. doi: 10.1212/01. wnl.0000282763.29778.59

2. Moulin DE, Boulanger A, Clark AJ, Clarke H, Dao T, Finley GA, et al. Pharmacological management of chronic neuropathic pain: Revised consensus statement from the Canadian Pain Society. Pain Res Manag. 2014;19(6):328-335.

3. Smith BH, Torrance N. Epidemiology of Neuropathic Pain and Its Impact on Quality of Life. Curr Pain Headache Rep. 2012;16(3):191-198. doi:10.1007/s11916-012-0256-0

4. Siddall PJ, McClelland JM, Rutkowski SB, Cousins MJ. A longitudinal study of the prevalence and characteristics of pain in the first 5 years following spinal cord injury. Pain. 2003;103(3):249-257.

5. van Hecke O, Austin SK, Khan RA, Smith BH, Torrance N. Neuropathic pain in the general population: a systematic review of epidemiological studies. Pain. 2014;155(4):654662. doi:10.1016/j.pain.2013.11.013

6. Iqbal Z, Azmi S, Yadav R, Ferdousi M, Kumar M, Cuthbertson DJ, et al. Diabetic Peripheral Neuropathy: Epidemiology, Diagnosis, and Pharmacotherapy. Clin Ther. 2018;40(6):828-849. doi:10.1016/j.clinthera.2018.04.001

7. Lu B, Yang Z, Wang M, Yang Z, Gong W, Yang Y, et al. High prevalence of diabetic neuropathy in population-based patients diagnosed with type 2 diabetes in the Shanghai downtown. Diabetes Res Clin Pract. 2010;88(3):289-294. doi:10.1016/j.diabres.2010.02.002

8. Pop-Busui R, Boulton AJM, Feldman EL, Bril V, Freeman R, Malik RA, et al. Diabetic Neuropathy: A Position Statement by the American Diabetes Association. Diabetes Care 2017;40(1):136-154. doi:10.2337/dc16-2042

9. Singh T, Chawla SPS, Gulia M, Kaur S. Pregabalin versus Gabapentin in the Management of Painful Diabetic Neuropathy. Sch Acad J Biosci. 2016;4(10A):805-810. doi: $10.21276 /$ sajb.2016.4.10.4

10. Bockbrader HN, Wesche D, Miller R, Chapel S, Janiczek $\mathrm{N}$, Burger P. A comparison of the pharmacokinetics and pharmacodynamics of pregabalin and gabapentin. Clin Pharmacokinetics. 2010;49(10):661-669. doi:10.2165/11536200-000000000-00000

11. Dworkin RH, O'Connor AB, Audette J, Baron R, Gourlay GK, Haanpaa ML, et al. Recommendations for the pharmacological management of neuropathic pain: An overview and literature update. Mayo Clin Proc. 2010;85(3Suppl):S3-S14 doi:10.4065/mcp.2009.0649

12. Finnerup NB, Attal N, Haroutounian S, McNicol E, Baron R, Dworkin RH, et al. Pharmacotherapy for neuropathic pain in adults: a systematic review and metaanalysis. Lancet Neurol. 2015;14(2):162-173. doi:10.1016/ S1474-4422(14)70251-0

13. Arnold LM, McCarberg BH, Clair AG, Whalen E, Thomas $\mathrm{N}$, Jorga $\mathrm{A}$, et al. Dose-response of pregabalin for diabetic peripheral neuropathy, postherpetic neuralgia, and fibromyalgia. Postgrad Med. 2017;129(8):921-933. doi:10.10 80/00325481.2017.1384691

14. Toth C. Pregabalin: latest safety evidence and clinical implications for the management of neuropathic pain. Ther Adv Drug Saf. 2014;5(1):38-56. doi: $10.1177 / 2042098613505614$
15. Fuzier R, Serres I, Guitton E, Lapeyre-Mestre M, Montastruc JL. Adverse drug reactions to gabapentin and pregabalin: a review of the French pharmacovigilance database. Drug Saf. 2013;36(1):55-62. doi: 10.1007/s40264-012-0006-6

16. Farrar JT, Polomano RC, Berlin JA, Strom BL. A Comparison of Change in the 0-10 Numeric Rating Scale to a Pain Relief Scale \& Global Medication Performance Scale in a Short-term Clinical Trial of Breakthrough Pain Intensity. Anesthesiology. 2010;112(6):1464-1472. doi:10.1097/ALN.0b013e3181de0e6d

17. Lombana WG, Vidal SEG. Pain and gender differences: A clinical approach. Colombia J Anesthesiol. 2012;40(3):207-212.

18. Serpell M, Latymer M, Almas M, Ortiz M, Parsons B, Prieto R. Neuropathic pain responds better to increased doses of pregabalin: an in-depth analysis of flexible-dose clinical trials. J Pain Res. 2017;10:1769-1776. doi: 10.2147/JPR.S129832

19. Wiffen PJ, Derry S, Bell RF, Rice ASC, Tölle TR, Phillips $\mathrm{T}$, Moore RA. Gabapentin for chronic neuropathic pain in adults. Cochrane Database Syst Rev. 2017;6:CD007938. doi:10.1002/14651858.CD007938.pub4

20. Hirakata M, Yoshida S, Tanaka-Mizuno S, Kuwauchi A, Kawakami K. Pregabalin Prescription for Neuropathic Pain and Fibromyalgia: A Descriptive Study Using Administrative Database in Japan. Pain Res Manag. 2018;2018:2786151. doi:10.1155/2018/2786151

21. Almas M, Parsons B, Whalen E. Prediction of therapeutic response to pregabalin in subjects with neuropathic pain. Curr Med Res Opin. 2018;34(12):2041-2052. doi:10.1080/03 007995.2018.1520694

22. Tzellos TG, Papazisis G, Amaniti E, Kouvelas D. Efficacy of pregabalin and gabapentin for neuropathic pain in spinalcord injury: An evidence-based evaluation of the literature. Eur J Clin Pharmacol. 2008;64(9):851-858. doi:10.1007/ s00228-008-0523-5

23. Robertson K, Marshman LA, Plummer D. Pregabalin and gabapentin for the treatment of sciatica. J Clin Neurosci. 2016;26:1-7.doi:10.1016/j.jocn.2015.05.061.

24. Lo YL, Cheong PWT, George JM, Tan SB, Yue WM, Guo $\mathrm{CM}$, et al. Pregabalin and Radicular Pain Study (PARPS) for Cervical Spondylosis in a Multiracial Asian Population. J Clin Med Res. 2014;6(1):66-71. doi:10.4021/jocmr879w

25. Ramamoorthy A, Pacanowski MA, Bull J, Zhang L. Racial/ ethnic differences in drug disposition and response: review of recently approved drugs. Clin Pharmacol Ther. 2015;97(3):263-273.

Authors' Contribution: AS conceived, designed, collected data, did statistical analysis and drafted manuscript. SMA and MK drafted manuscript, reviewed and did final approval of manuscript. AA conceived and designed study, collected data and reviewed manuscript.

\section{Authors:}

1. Abida Shaheen, MPhil.

Associate Professor, Pharmacology, Shifa College of Medicine, Shifa Tameer-e-Millat University, Islamabad, Pakistan.

2. Syed Mahboob Alam, PhD. Associate Professor, Pharmacology, Basic Medical Sciences Institute, JPMC, Karachi, Pakistan.

3. Arsalan Ahmad, MD. Professor, Neurology, Shifa College of Medicine, Islamabad, Pakistan.

4. Moosa Khan, PhD. Associate Professor, Pharmacology, Shaheed Zulfiqar Ali Bhutto Medical University, Islamabad, Pakistan. 